\title{
USO DE DROGAS ENTRE TRABALHADORES PRECOCES NA ATIVIDADE DE MALABARES ${ }^{1}$
}

\author{
Daniele Cristine da Silva Cirino* \\ Maria de Fátima Pereira Alberto\#
}

\begin{abstract}
RESUMO. O presente estudo objetiva identificar os fatores que motivam o uso de drogas entre meninos trabalhadores em condição de rua na cidade de João Pessoa - PB, caracterizar a atividade de trabalho de malabares e relacionar o trabalho precoce e o uso de drogas com as perspectivas de futuro destes sujeitos. A pesquisa desenvolveu-se através da territorialização, observação e registro assistemático e entrevistas semiestruturadas, com dados analisados a partir da análise de conteúdo de Bardin (1979). Foram entrevistados seis sujeitos, entre 11 e 16 anos, todos do sexo masculino. As drogas utilizadas por eles foram bebidas alcoólicas, cigarro, cola e maconha. Os motivos para o uso foram a imposição do grupo e o desconhecimento dos reais efeitos das drogas. Constatamos ainda que, para os trabalhadores precoces no setor informal urbano, há construção de perspectivas de futuro, vislumbradas através da inserção profissional quando adultos, possível de se concretizar a partir da escola.
\end{abstract}

Palavras-chave: drogas, trabalho precoce, meninos em condição de rua.

\section{USE OF DRUGS BETWEEN PRECOCIOUS WORKERS IN THE ACTIVITY OF JUGGLERS}

\begin{abstract}
This study aims to identify the factors that motivate the use of drugs among diligent boys in street condition in the city of João Pessoa - PB; to characterize the work activity of jugglers and to relate the precocious work and the use of drugs with the future perspectives of these citizens. The research was developed through the territorialization, comment and unsystematic register and half-structuralized interviews, with analyzed data from the content's analysis of Bardin (1979). 06 citizens were interviewed, between 11 and 16 years old, all of the masculine sex. The drugs used by them were alcoholic beverages, cigarette, glue and marijuana. The reasons to use them were the group's imposition and the unfamiliarity of the real effect of drugs. We still verified that for the precocious workers there is the construction of future perspectives glimpsed through their professional insertion when adult, possible to be realized from the school.
\end{abstract}

Key words: Drugs, precocious work, boys in street condition.

\section{USO DE DROGAS ENTRE TRABAJADORES PRECOCES EN LA ACTIVIDAD DE MALABARISTA}

RESUMEN. Esta investigación trata de identificar los factores que motivan el uso de drogas entre niños trabajadores en condición de calle de la ciudad de João Pessoa - PB; caracterizar la actividad de trabajo de malabaristas y relacionar trabajo precoz y uso de drogas con las perspectivas de futuro de estos niños. Se utilizó como técnicas: "territorialización" (conocimiento previo del sitio), observación y registro no sistemáticos y entrevistas semidirigidas, con datos analizados por medio del análisis de contenido de Bardin (1979). Fueron entrevistados 06 niños, entre 11 y 16 años, del sexo masculino. Las drogas utilizadas por ellos fueron bebidas alcohólicas, cigarrillo, inhalantes y marihuana. Los motivos para el uso fueron: imposición del grupo y desconocimiento de los efectos reales de las drogas. Constatamos, todavía, que existe construcción de perspectivas de futuro para estos trabajadores a partir de la inserción profesional cuando adultos, susceptible de concretización por medio de la escuela.

Palabras-clave: Drogas, trabajo precoz, niños en condición de calle.

Este artigo é um fragmento de Monografia em Psicologia pela Universidade Federal da Paraíba/UFPB (2006).

* Psicóloga. Graduada pela Universidade Federal da Paraíba/UFPB. Membro do Núcleo de Pesquisa sobre o Desenvolvimento da Infância e Adolescência em Situação de Risco Pessoal e Social/UFPB.

\# Doutora em Sociologia. Professora Adjunta do Departamento de Psicologia e do Programa de Pós-Graduação em Psicologia Social da Universidade Federal da Paraíba, Coordenadora do Núcleo de Pesquisa sobre o Desenvolvimento da Infância e Adolescência em Situação de Risco Pessoal e Social/UFPB. 
O objetivo deste estudo é identificar os fatores que motivam o uso de drogas entre trabalhadores precoces em condição de rua, na atividade de malabares, na cidade de João Pessoa - PB. Apresenta também aspectos específicos, como a caracterização da atividade de trabalho, a partir da qual se identificaram crianças e adolescentes trabalhadores que fazem (ou fizeram) uso de drogas, além da relação entre o trabalho precoce e o uso de drogas com as perspectivas de futuro desses trabalhadores.

A referida atividade foi selecionada por dois fatores: ser uma prática relativamente nova entre as atividades informais realizadas por crianças e adolescentes em condição de rua de João Pessoa; e ser percebida, tanto por estes quanto por transeuntes, como brincadeira e diversão, uma vez que estes elementos são frequentemente associados ao malabarismo. Representa, dessa forma, uma atividade na qual o trabalho precoce e situações de exploração como o incentivo ao uso de drogas e o trabalho no tráfico - podem ser mais facilmente confundidos ou camuflados pelos aspectos lúdicos que permeiam a atividade. Um fato observado foi que, para os entrevistados, tanto a ocupação quanto a atividade desempenhada por eles são denominadas malabares. Assim, iremos nos referir às crianças e aos adolescentes entrevistados como meninos malabares.

A expressão em condição de rua, para crianças e adolescentes trabalhadores precoces, reflete a sua condição de permanência nas ruas durante a realização de sua atividade de trabalho. Para Minayo (1993), tal expressão se refere a crianças e adolescentes que utilizam a rua como espaço de trabalho e sustento e retornam assiduamente para suas casas por ainda manterem os laços familiares. Refere-se também àqueles que vivem nas ruas com suas famílias, ou ainda àqueles que se encontram em processo de rompimento ou que já romperam em definitivo o contato familiar.

Alguns autores (Koller \& Hutz, 1996; Minayo, 1993) se dedicaram a explicar a confusão terminológica que permeava - e ainda permeia - os conceitos "meninos de rua" e "meninos na rua". Grasciani (1997) apresenta as categorias "meninos (as) na rua" para caracterizar aqueles que ainda mantêm vínculos com a família; e "meninos (as) de rua", para os que já romperam todos os laços e vivem na rua. Alberto (2002), no entanto, contesta esta última definição, por pressupor um estado, algo parado, e por conduzir a uma imagem estigmatizada e pejorativa. Sua pesquisa assinalou que essas crianças não são "de rua", e sim, estão "em condição de rua" em um determinado momento de sua vida, especificando o caráter passageiro da situação. A rua funciona como espaço de socialização e parte do processo de formação de crianças e adolescentes, o que não quer dizer que permanecerão nela o resto da vida.

Nesta pesquisa, foi utilizada a categoria "meninos em condição de rua", definida como crianças e adolescentes que passam a maior parte dos dias nas ruas, desacompanhados, retirando, mediante o trabalho informal ou atos ilícitos, o seu sustento ou o de suas famílias. Têm, portanto, família, mas podem viver ou não viver com ela cotidianamente, variando, desta forma, a qualidade e a duração de contato. A mobilidade expressa por eles, a existência da família e o tipo de contato, além do fato de se encontrarem desacompanhados nas ruas, são as características que levam a sugerir esta outra terminologia.

Alberto (2002) aponta, ainda, que a presença dos meninos e das meninas nas ruas trabalhando está ligada a diversos fatores de ordem macro e microestrutural. De ordem macroestrutural são todos aqueles fatores sociais, políticos e econômicos que forjam a necessidade de a família enviar seus filhos ao mercado de trabalho: a tecnologia e a flexibilização do mercado de trabalho, o acirramento das forças produtivas, a transformação e a precarização das relações e condições de trabalho e as políticas econômicas recessivas, além de fatores climáticos e da mecanização da lavoura, forçando a saída de famílias das zonas rurais para os centros urbanos. Para a autora, estes fatores promovem a geração de pobreza, desemprego ou renda insuficiente para o sustento da família, que, por não mais conseguir atender às necessidades materiais e subjetivas dos filhos, acaba por empurrá-los para as ruas.

Outros autores (Kassouf, 2005; Campos \& Alverga, 2001; Oliveira \& Robazzi, 2001) também apontam uma visão macro: é a necessidade de garantir a própria sobrevivência ou a complementação do orçamento familiar que leva crianças e adolescentes ao trabalho, ou seja, é a pobreza que obriga as famílias a adotarem formas de comportamento que incluem a oferta de mão-de-obra dos filhos menores de idade. Assim, o crescente número de crianças e adolescentes ocupados no mercado informal reflete o empobrecimento e a má distribuição de renda do país, pois quanto maior o índice de desemprego, maior também o número de trabalhadores ocupados em subempregos, como forma de garantir uma renda que possibilite a subsistência da família.

Há autores que acrescentam a esses fatores os aspectos sociais ligados às políticas públicas, como direitos sociais, ou à falta de equipamentos 
institucionais (Moreira \& Stengel, 2003), além de um mercado que oportuniza, ou seja, um mercado consumidor de mão-de-obra infantil no setor informal, particularmente em condição de rua, quer contratando, quer consumindo, e de uma rede que recruta formada por familiares ou por membros da comunidade. Esta rede consegue a vaga, leva a criança ou adolescente e garante sua permanência nas atividades (Alberto, 2006).

Os fatores de ordem micro-estrutural (Prado \& Gomes, citados por Minayo, 1993) são ligados aos conflitos interpessoais que permeiam as relações familiares e são responsáveis pela ida para a rua, principalmente nos casos das crianças que se encontram em processo de rompimento com o núcleo familiar.

Estes fatores, acrescidos aos aspectos de ordem cultural, à importância que a família dá ao trabalho, ao imaginário social acerca do trabalho como antídoto para a marginalidade e à falta de equipamentos institucionais, permitem a utilização de mão-de-obra infantil e adolescente, inserida no mercado informal de rua, e recriam formas de trabalho que propiciam a obtenção de determinado faturamento, utilizando-se de estratégias e de seu poder criativo para sensibilizar o comprador por sua condição, e assim garantir a venda de um produto - no caso, uma atração (Cruz \& Assunção, 2008; Marques, 2001).

Em João Pessoa, o trabalho precoce no setor informal se destaca em atividades exercidas em oficinas mecânicas, padarias, bares, lanchonetes (quiosques), e em atividades como catador de lixo, distribuidor de jornal, vendedor ambulante, biscateiro, engraxate, olheiro de carros, lavador de carro, ajudante de empresas de fundo de quintal, ajudante de feirantes e barraqueiros, doméstica, carregador de feiras (fretistas), além de exploração sexual comercial, pesca (inclusive submarina), tráfico de drogas, furtos e assaltos. Nos três últimos, são usados pelo crime organizado (Delegacia Regional do Trabalho, 2007; Alberto, 2002).

Além destes, existe o ramo de atividade mais atual, identificada como o de malabaristas: crianças e adolescentes que realizam a atividade de malabaristas nos sinais de trânsito. Eles aproveitam o sinal fechado e apresentam-se, esperando receber em troca $o$ pagamento das pessoas. O malabarismo consiste em uma prática, idêntica à circense, de jogar para o alto pedaços de madeira retirados das ruas ou limões comprados em supermercados, que servem, respectivamente, como bastões e bolas na realização da apresentação (Procuradoria Regional do Trabalho, 2004).
Trata-se, portanto, de uma atividade realizada em condição de rua e que, apesar de existirem autores que enfatizem processos de resiliência e proteção contra os riscos como possibilidade de desenvolvimento (Paludo \& Koller, 2005; Cecconello, 2003; Yunes, 2001; entre outros), e por considerarmos a referida questão como importante, este artigo analisará o trabalho precoce na atividade de malabares a partir dos impactos ou implicações relacionados à inserção precoce no trabalho e à exposição nas ruas, como atividade que compromete a infância e o desenvolvimento psicossocial de crianças e adolescentes (Kassouf, 2005; Marques, 2001).

Os efeitos são heterogêneos, considerando-se que o trabalho na rua, especificamente para crianças e adolescentes, relaciona-se a uma série de aspectos que dizem respeito às condições de trabalho, à família, à escola, à organização do trabalho e ao desenvolvimento psicossocial. $\mathrm{O}$ trabalho precoce no setor informal produz efeitos discriminatórios, pois a criança e o adolescente têm seus direitos humanos fundamentais violados e não têm acesso aos aspectos inerentes e imprescindíveis ao desenvolvimento físico, mental, moral, espiritual e social (Alberto, 2002; Oliveira \& Robazzi, 2001). Dessa forma, o trabalho de crianças e de adolescentes em condição de rua acaba por ser confundido com a própria condição de rua, e estes passam muitas vezes a ser vistos pela população como marginais, trombadinhas, pivetes ou designados por quaisquer outros termos de cunho pejorativo. Passa despercebida, assim, a sua condição de trabalhador precoce.

No caso dos adolescentes em condição de rua, segundo Alves et al. (citados por Neiva-Silva \& Koller, 2002), estes "procuram sistematicamente a companhia de adultos na rua, nem sempre seus cuidadores, mas conhecidos ou pessoas com quem podem conseguir alguma ajuda" (p.116). Deste modo, ficam mais propensos à ação e influência de adultos que se aproximam, na verdade, com a intenção de explorar o seu trabalho, bem como de aliciá-los para práticas ilícitas, como uso ou tráfico de drogas.

A rua pode ser percebida, então, não apenas como local no qual serão desenvolvidas as atividades referentes ao trabalho de crianças e adolescentes, mas também como espaço no qual eles se encontram vulneráveis a uma socialização desviante, com consequente exposição às drogas. A socialização desviante é entendida como o acesso ou ingresso em atividades que conduzem à socialização com delitos e com atos infracionais, podendo encaminhá-los à marginalidade. A rua não determina isto, mas o facilita pelos tipos de relações sociais que propicia, entre as 
quais a exploração sexual comercial, a violência e o acesso às drogas.

\section{METODOLOGIA}

\section{Participantes}

Participaram deste estudo seis crianças e adolescentes trabalhadores precoces em condição de rua da cidade de João Pessoa - PB, com idade entre 11 e 16 anos, do sexo masculino, encontrados realizando a atividade de malabares nos sinais da cidade de João Pessoa. A ausência de meninas neste estudo se deu pelo motivo de não terem sido encontradas realizando esse tipo de atividade, embora o relato de alguns meninos afirmasse a sua presença.

Para este trabalho, adotou-se, na delimitação da amostra, o critério da saturação, uma vez que, de acordo com Sá (1998), no decorrer da pesquisa, quando os temas começam a se repetir, é sinal de que entrevistar uma maior quantidade de sujeitos pouco acrescentaria de significativo ao conteúdo já apreendido pelas falas, podendo-se, então, realizar mais umas poucas entrevistas e parar.

\section{Instrumentos}

Foi utilizada uma entrevista individual semiestruturada, com o objetivo de: a) caracterizar a atividade de trabalho de malabares desempenhada por crianças e adolescentes em condição de rua; b) analisar o nível de conhecimento sobre drogas; e c) investigar as perspectivas de futuro.

$\mathrm{Na}$ análise dos dados, o conteúdo das entrevistas individuais com roteiro semiestruturado foi trabalhado a partir da técnica de análise de conteúdo temático (Bardin, 1979), fazendo-se emergir os núcleos de sentido da presença ou ausência do tema.

Dessa forma, gravadas as entrevistas, seus resultados foram analisados e interpretados, obedecendo-se à seguinte forma: (a) organização dos dados, através da transcrição das fitas, digitação e leitura flutuante do material, além da organização dos relatos e das observações, com a finalidade de se registrar e se organizar o material do discurso coletado na entrevista, além de se estabelecer contato com tal material; (b) tabulação, codificação e categorização dos dados, com a finalidade de fazer o recorte das unidades temáticas, agrupar o recorte destas para construção das categorias e apresentar uma representação simplificada do conteúdo emergente do discurso do sujeito; e (c) análise final, com as inferências e interpretações das pesquisadoras acerca dos relatos apresentados, relacionado-os com o objeto proposto para investigação e com os autores de referência.

\section{Procedimentos}

Utilizaram-se como técnicas de pesquisa três conjuntos de procedimentos: a territorialização, a observação e registro assistemático e a entrevista individual semiestruturada.

A territorialização é descrita em Alberto (2002) como uma técnica específica de aproximação ao espaço da rua - local de domínio dos sujeitos, com a finalidade de facilitar o contato com eles, uma vez que as pesquisadoras eram pessoas estranhas àquele território. Segundo Grasciani (1997), a territorialização propicia o início dos contatos e a realização de uma observação razoável do contexto no qual a criança e o adolescente se encontram inseridos, além de permitir que estes comecem a perceber quem somos e os dias e horários em que estamos na rua. Permite-nos, também, perceber o melhor dia, horário e local para encontrá-los, seus nomes (verdadeiros ou não), suas atividades e seu modo de viver na rua.

Conjuntamente com a territorialização, foram realizados a observação e o registro assistemático da atividade desempenhada pelos sujeitos, com a finalidade de se perceber em quais horários estes se encontravam no local e quais horários seriam mais propícios à abordagem para a entrevista, além da caracterização da atividade de trabalho. $\mathrm{O}$ registro das observações das pesquisadoras foi feito por meio de anotações que compuseram um diário de campo. Em um momento seguinte, foi realizado o contato direto com os sujeitos para identificação das pesquisadoras e esclarecimentos acerca dos objetivos do estudo. Tendo a criança ou o adolescente aceitado participar do estudo, combinou-se um local, dia e horário para a realização da entrevista.

A parte de pesquisa de campo deste estudo foi desenvolvida por duas pesquisadoras, sendo escolhida esta alternativa pelo fato de se encontrar no local mais de uma criança ou adolescente, o que levava a interrupções das entrevistas individuais. Dessa forma, enquanto uma pesquisadora realizava a entrevista, a outra distraía os demais.

A pesquisa realizou-se em pontos de maior concentração de crianças e adolescentes trabalhadores na cidade de João Pessoa, mais especificamente na atividade de malabares, que são os sinais de trânsito. Estes são locais estratégicos para os malabares, devido à parada obrigatória dos carros, tempo aproveitado para realizarem a apresentação do malabarismo e recolherem dinheiro junto aos carros. Os referidos 
sinais localizam-se em uma área de trânsito intenso e de permanente passagem de veículos, reunindo, desta forma, constante número de sujeitos realizando a atividade.

Em cada um destes cruzamentos podem ser encontrados diariamente cerca de três a quatro crianças e adolescentes. Este número pode variar, dependendo da demanda de veículos no local e da hora em que a atividade esteja sendo realizada. Estes pontos têm, em comum, locais onde os meninos podem sentar-se para lanchar, abrigar-se ou descansar enquanto o sinal está aberto para os carros.

\section{RESULTADOS E DISCUSSÃO}

\section{Caracterização da atividade de trabalho}

Uma vez que o objetivo principal desta pesquisa era identificar os fatores que motivam o uso de drogas entre crianças e adolescentes trabalhadores em condição de rua, fez-se necessária uma investigação acerca da atividade desempenhada pelos sujeitos no sentido de identificar trabalhadores precoces e compreender a atividade desempenhada por eles, além de identificar fatores que relacionem o trabalho com o uso de drogas.

Com relação ao que fazem nas ruas, todos os sujeitos afirmaram realizar a atividade de malabares, sendo alguns associados a outras atividades, como olheiro, fretista e descarregador de caminhão.

Afirmaram que começaram a trabalhar nas ruas entre 7 e 14 anos, com o intuito de ganhar dinheiro e de contribuir para o sustento da família, ou, ainda, pelo deslumbramento que a rua provoca, apontando-a como local de "liberdade", onde não precisam dar satisfações a terceiros e onde têm, ainda, a possibilidade de ganhar seu próprio dinheiro. Para Koller e Hutz (1996), esta referência à busca de liberdade não deve ser interpretada como uma busca pela amplidão da rua, pela falta de controle parental e de ausência de limites, mas sim, como uma busca pela libertação do abuso e da exploração a que, em muitos casos, estas crianças e adolescentes se encontram submetidos no convívio familiar.

Apontaram também o "senso de utilidade", referente ao discurso de que não trabalhar nesta idade é sinônimo de vadiagem. Além de iniciarem a atividade "por diversão", realizam a atividade de malabares por considerarem-na uma brincadeira. Constatou-se que, em alguns casos, os trabalhadores precoces se utilizam da atividade de trabalho como recurso lúdico, uma vez que estes elementos são frequentemente associados ao malabarismo. Dessa forma, as brincadeiras aliviam a angústia e o sofrimento do trabalho precoce e dos riscos, propiciando prazer.

Os referenciais teóricos sobre trabalho e saúde afirmam que, para o trabalhador adulto, reconhecer o sofrimento do trabalho não é uma tarefa fácil, por vários aspectos: ou porque não têm conhecimento sobre as implicações, ou porque reconhecê-lo seria desmontar as estratégias de defesa (Dejours, Abdoucheli \& Jayet, 1994). Se isso é verdadeiro para adultos, mais ainda para crianças e adolescentes.

Os motivos pelos quais começaram a trabalhar, tanto de ordem econômica quanto de ordem pessoal, corroboram os resultados dos autores que identificam que as causas da inserção precoce no trabalho residem em fatores macro (Kassouf, 2005; Moreira \& Stengel, 2003; Campos \& Alverga, 2001) e microestruturais (Minayo, 1993).

A idade em que começaram a trabalhar também corrobora os achados de outros autores (Kassouf, 2005; Procuradoria Regional do Trabalho, 2004) sendo a faixa etária mais vulnerável a iniciar-se no trabalho nas atividades informais de rua a de 8 a 12 anos. Isto nos permite compreender que essas são as idades que demandam maior número de políticas públicas, principalmente aquelas destinadas à prevenção do trabalho da criança. Além disso, esta faixa corresponde àquela cuja escolaridade é obrigatória, o que poderia indicar um maior investimento na educação desses sujeitos.

Desta forma entendemos que, para crianças e adolescentes das classes populares, as necessidades de sobrevivência repercutirão em sua adultização precoce - o que significa assumirem mais cedo as responsabilidades por si mesmos e pela própria família, com o ingresso no mercado de trabalho. Uma vez no trabalho, principalmente em condição de rua, estarão vulneráveis à socialização desviante, especialmente ao uso de drogas (Marques, 2001; Campos, Del Prette \& Del Prette, 2000).

Oliveira e Robazzi (2001) apontam que a necessidade ou vontade de ganhar o próprio dinheiro é um tema recorrente entre os motivos que impulsionam crianças e, particularmente, adolescentes para o trabalho. Desta forma, ganham a possibilidade de complementar a renda familiar e suprir as próprias necessidades ou desejos, como também, trabalhando desde pequenos, aprendem a ideia de valorizar o que ganham com o próprio esforço.

Com relação ao que fazem com o dinheiro que ganham, afirmaram que o dão aos familiares (pai, mãe), entregam-no a terceiros ou ficam com ele. Terceiros são aquelas pessoas que eles conheceram 
nas ruas e que lhes ofereceram abrigo permanente ou temporário, que os "protegem" dos riscos das ruas ou exploram sua mão-de-obra. Dessa forma, para complementar a renda familiar, a criança e o adolescente vão ocupando cada vez mais postos de trabalho que antes eram ocupados por adultos, proporcionando, assim, a sobrevivência do setor informal a custas do trabalho infantil (Kassouf, 2005).

Sobre quanto ganham por dia de trabalho, os dados mostram que os sujeitos recebem valores diários que variam de $\mathrm{R} \$ 3,00$ a $\mathrm{R} \$ 27,00$ reais, podendo trabalhar todos os dias ou em dias alternados, com jornadas de 10 a 15 horas diárias.

Os sujeitos identificam como aspecto positivo do trabalho nas ruas a venda de produtos ou a junção de mais de uma atividade, tal como a de olhar carro e de malabares, uma vez que produz maior rentabilidade do que a atividade de malabares realizada de forma isolada. Esses dados demonstram a dupla ou tripla jornada a que esses sujeitos muitas vezes se encontram submetidos e que pode ser extremamente nefasta ao seu desenvolvimento, uma vez que essa carga contribui para a compreensão do atraso escolar desses sujeitos. O trabalho torna-se, assim, um fator que compromete o estudo, pois leva essas crianças e adolescentes a não frequentarem a escola, provocando, então, a evasão escolar e a socialização desviante (Cruz \& Assunção, 2008; Campos \& Alverga, 2001).

Como aspecto negativo do trabalho nas ruas enfatizaram a mendicância, devido ao receio com que são vistos por outras pessoas, as más influências e ao risco de morte. Pode-se perceber a rua como local propenso ao envolvimento com pessoas de caráter duvidoso, que gera uma socialização desviante, com possível envolvimento com drogas, furtos, etc., além do risco de, ao estarem dormindo na rua, serem agredidos ou mesmo mortos por outras pessoas.

Os sujeitos afirmaram ter aprendido a fazer malabarismos sozinhos, ou seja, através da observação, ou que aprenderam com amigos através da experiência destes na rua. Percebemos que os dados corroboram os de Alberto (2002), que, ao investigar trabalhadores informais em condição de rua em João Pessoa, constatou que a destreza necessária é adquirida na realização da atividade de trabalho. A forma de inserção, por sua vez, inscreve-se num sistema de redes de solidariedade que estrutura as atividades de trabalho informais: amizade e parentesco. A aprendizagem se dá mediante a transmissão oral e a prática das tarefas, que inicialmente são feitas pela pessoa que os inseriu naquela atividade e têm continuidade com a observação do desempenho das tarefas pelos demais trabalhadores.

Dessa forma, as ruas acabam por se transformar, para estes sujeitos, em locais de trabalho, onde desempenham suas atividades mas também se tornam vulneráveis a vários tipos de violências, entre as quais se podem citar agressões físicas e verbais, a exploração do próprio trabalho, a socialização desviante com exposição às drogas.

\section{Conhecimento sobre drogas e o seu uso por crianças e adolescentes malabares}

Uma vez identificados como crianças e adolescentes trabalhadores precoces, os sujeitos foram indagados acerca do conhecimento sobre drogas. Todos afirmaram ter algum conhecimento e quatro deles afirmaram ter feito uso de substâncias psicoativas e ter começado a utilizá-las entre os 8 e os 14 anos. As drogas por eles utilizadas, por ordem de maior frequência, foram bebidas alcoólicas, cigarro, cola e maconha.

Os motivos pelos quais fizeram uso foram o medo - pela imposição do grupo como forma de inserção ritual, sob a forma de coação - por pensarem que era bom e por quererem experimentar. Estes dados corroboram os achados de outros autores (Alberto \& Mariano, 2003; Campos, Del Prette \& Del Prette, 2000) e revelam que o uso de drogas também se dá pelo desconhecimento dos seus reais efeitos ou pela vontade de utilizá-las. Considerando-se esses aspectos, percebe-se que a droga é um fenômeno grupal. No caso dos meninos, é um instrumento para a inserção de alguém que, saindo de casa, precisa pertencer, ter um grupo de referência para ser aceito e sobreviver. Há também a curiosidade de conhecer a droga, de saber o que é e como funciona no corpo enquanto capacidade alucinógena e provocadora de sensações, de entorpecimentos, de devaneios e de fugas do estado de consciência (Alberto \& Mariano, 2003).

Os sujeitos afirmaram ainda ter conseguido a droga: por meio de amigos que também se encontram em condição de rua; em feiras livres, por meio de feirantes e barraqueiros; e na orla marítima, referindose às bebidas alcoólicas compradas pelas crianças e pelos adolescentes em barracas na praia, mesmo sendo a sua venda proibida por lei para menores de 18 anos (ECA, 1990). Afirmaram também que as drogas são conseguidas "através de outras pessoas que oferecem... tem uns "grandes" que oferecem... pra viciado mesmo" (F., 15 anos), referindo-se a traficantes que atuam nas proximidades. Além disso, para alguns dos entrevistados, a concepção de drogas se estende apenas às drogas tidas como ilícitas. As 
lícitas, como cigarro e álcool, não são compreendidas como drogas, apesar de demonstrarem possuir conhecimento acerca dos seus malefícios à saúde.

Dos sujeitos entrevistados, apenas um afirmou ainda fazer uso de algum tipo de droga. Os que deixaram de fazê-lo apontaram como motivos a possibilidade de morrer em decorrência do uso, o fato de as drogas deixarem "doidão", as brigas ou o fato de estragarem os dentes e fazerem mal aos pulmões. $\mathrm{O}$ que ainda faz uso afirma não sentir os efeitos da droga. Para Alberto e Mariano (2003), dizer que não sente nada é a representação ou a tentativa de desmistificar, em parte, o poder atribuído à droga, e, para estes meninos, as drogas não provocam nenhuma reação. Neste caso, isto pode ser entendido como uma forma utilizada pelo adolescente para provar que, mesmo fazendo uso de drogas, não perde o controle sobre suas ações e que elas não provocam alterações em seu comportamento ou em suas emoções.

Os sujeitos apontaram como consequências do uso de drogas na vida das pessoas a vontade de roubar e de "judiar" de outras pessoas, o envolvimento com brigas, a morte, a prisão e "ficar doido", que, no imaginário social brasileiro, é o louco, aquele que não dá conta de si ou que não sabe o que faz - o que vem, na percepção dos sujeitos, justificar determinados tipos de comportamento, uma vez que, em "sã consciência", uma pessoa não reagiria de determinada forma.

Sobre já terem precisado vender algum tipo de droga, todos os entrevistados afirmaram que não. Não obstante, dois sujeitos afirmaram já ter sido abordados por terceiros para comprar drogas. Ambos disseram não ter aceitado a proposta e apontaram como motivo, um deles, o medo de ser preso, uma vez que o pai de um dos sujeitos se encontra preso por tráfico de drogas, e o outro, que o local onde se vendem drogas é perigoso a partir de determinada hora.

Para alguns autores, a família possui papel preponderante no desenvolvimento de crianças e adolescentes, uma vez que, em alguns casos, ela pode desencadear o envolvimento dos filhos com as drogas, como no caso de ambientes familiares de relacionamentos conflitivos, instáveis e violentos (Sidman, 1995), ou no caso de a própria estrutura familiar utilizar-se de substâncias psicoativas como medicamentos, bebidas alcoólicas e outros (Carlini, Carlini-Cotrim \& Silva Filho, 1990). Neste sentido, para crianças e adolescentes que recorrem ao uso de drogas, estas se apresentam como meio que proporciona a ilusão de aparente bem-estar, de possibilidade de isolar angústias, de dar vazão a anseios, tensões e insatisfações ante um mundo que se apresenta ameaçador e violento.

Todos os sujeitos afirmaram já ter sido abordados tanto pela polícia quanto pelo Conselho Tutelar para serem encaminhados de volta para casa. Pode-se perceber que, para estas crianças e adolescentes, a volta para casa constitui-se um problema, uma vez que envolve a preocupação com as condições financeiras das famílias de origem, pois o retorno ao lar implica falta de dinheiro ou da complementação de renda para suas famílias.

Acerca de problemas com outros grupos, apontaram o roubo de seu dinheiro por "cheira-colas" que perambulam pelas ruas. $\mathrm{O}$ fato de os sujeitos encontrarem-se em grupos ressalta bem este aspecto da ameaça constante e da necessidade de proteger-se dos outros atores que permeiam o cotidiano da rua.

Por meio dos dados, identificou-se que, para a maioria das crianças e dos adolescentes, a responsabilidade pelo uso da droga reside prioritariamente no próprio sujeito; no entanto afirmam que este, sozinho, não é capaz de livrar-se da dependência, tendo que recorrer à mãe, a amigos ou a qualquer outra pessoa que realize o papel de aconselhador. Sobre o que poderia ser feito por essas pessoas, responderam que poderiam ser aconselhadas, presas ou que apenas o carinho da mãe poderia ajudálas. Para outros sujeitos, a responsabilidade do uso das drogas reside naquele que oferece a droga e que leva uma pessoa a drogar-se; ou seja, o sujeito é vítima de terceiros que oferecem o produto.

Os dados refletem que as crianças e os adolescentes trabalhadores em condição de rua encontram-se frequentemente expostos ao uso de drogas, não só pelo trabalho, mas principalmente pelo fato de este, realizado em condição de rua, promover o acesso a uma socialização desviante.

\section{Perspectivas de futuro}

Este tema foi abordado por ser entendido como um aspecto ligado diretamente à saúde mental do trabalhador, principalmente se relacionado a crianças e adolescentes trabalhadores precoces em condição de rua que utilizam ou utilizaram algum tipo de droga.

Quando indagados sobre o que desejam ser no futuro, as respostas se traduziram em ocupações profissionais ligadas à celebridade (jogador de futebol) e àquelas representativas de uma cultura trabalhadora (motorista, fazendeiro e trabalhador formal). Para um dos sujeitos entrevistados, a vontade de "ser trabalhador" no futuro explicita seu desejo de possuir um emprego formal com carteira assinada. Foi observado que esse adolescente se reconhece como 
trabalhador em sua condição de rua, mas o trabalho formal the traria o reconhecimento do outro, além de uma remuneração certa e fixa. Percebemos desta forma que, para esses trabalhadores precoces do setor informal que se utilizam ou utilizaram algum tipo de droga, ainda há construção de perspectivas de futuro, vislumbradas a partir de uma inserção profissional quando adultos, o que corrobora dados de Alberto (2006).

Sobre se o que fazem hoje possibilitará o alcance destas perspectivas de futuro, a maioria dos sujeitos respondeu que não. Para eles, a realização dos seus desejos se concretiza a partir da ausência de contato com as drogas e do retorno à escola, o que vem confirmar o papel atribuído a esta de instrumento mais eficaz para ser usado no enfrentamento do trabalho precoce (Fórum, 2004; OIT, 2001) e do uso de drogas por crianças e adolescentes, mediante a educação preventiva (Moura, 2004).

Percebemos que, para alguns sujeitos, pensar em termos de perspectivas de futuro remete a algo inatingível: "Eu sonho demais... o caba nunca chega não a realizar não...” (R., 14 anos). Dejours (1986) relaciona o conceito de saúde ao de ter esperança e desejo, pois, para ele, o verdadeiro perigo existe quando não há mais desejo. Na falta deste, o corpo pode adoecer mais facilmente. Se um fator de perigo é a ausência do desejo, então, quando as crianças e os adolescentes não apresentam perspectivas de futuro, podemos entender que eles não têm desejo. Entendemos este fato como danoso para a saúde psíquica, assim o desenvolvimento desses sujeitos encontra-se comprometido.

Sobre se gostariam de parar de trabalhar na rua, todos responderam que sim, apresentando como fatores motivadores: desejo de retorno ao convívio familiar; riscos ligados à atividade (atropelamentos); desejo de retorno às atividades escolares; maus-tratos sofridos nas ruas; desejo do trabalho formal, além do risco de uso e abuso de drogas e de aliciamento pelo tráfico.

Por estes dados se percebe que os trabalhadores precoces do setor informal desejam não precisar mais trabalhar, devido tanto ao conjunto de riscos a que estão expostos no decorrer da atividade de trabalho quanto aos riscos sociais (Oliveira \& Robazzi, 2001; Campos \& Alverga, 2001): riscos de exposição às drogas, violências (abusos, tráfico), perigos à formação moral, afastamento da família e da comunidade, além do prejuízo da escolaridade. Percebeu-se ainda, pelo discurso dos sujeitos, que o medo também se constitui como fator motivador para se deixar o trabalho, o que corrobora os dados de
Alberto (2002), que aponta que este medo deriva das situações de violência, dos perigos e dos riscos decorrentes da condição de rua, além do medo de o trabalho não propiciar o alcance de suas perspectivas de futuro.

\section{CONSIDERAÇÕES FINAIS}

Os dados permitem perceber que as crianças e os adolescentes inseridos na atividade de malabares possuem conhecimento acerca de drogas e que, já em condição de rua, fizeram ou ainda fazem uso de alguma substância psicoativa. Os fatores motivadores para o uso variam desde a imposição do grupo - sob forma de inserção ritual, mediante coação - até o desconhecimento dos seus reais efeitos ou sentirem vontade de utilizá-la.

Esses sujeitos têm consciência de que, se ficarem nas atividades informais, recorrerem ao uso de drogas e não regressarem às atividades escolares, dificilmente terão possibilidade de realizar-se profissionalmente e assim atingir suas perspectivas de futuro, permanecendo, dessa forma, à margem de uma concepção valorizada de profissão que venha possibilitar-lhes a efetivação de seus direitos enquanto cidadãos.

De forma geral, esta pesquisa contribui no sentido de apontar os riscos que permeiam uma atividade de trabalho realizada por crianças e adolescentes em condição de rua e os danos ao seu desenvolvimento biopsicossocial. Espera-se ainda que este trabalho possa contribuir para a discussão da necessidade de erradicação do trabalho de crianças e para a efetiva garantia dos direitos dos adolescentes trabalhadores.

\section{REFERÊNCIAS}

Alberto, M. F. P. (Coord.) (2006). O trabalho infantil na atividade informal urbana em Guarabira-PB: um diagnóstico rápido à luz. das piores formas do trabalho infantil. Brasília: IPEC/OIT/Secretaria Internacional do Trabalho.

Alberto, M. F. P. (2002). Dimensões subjetivas do trabalho precoce de meninos em condição de rua em João Pessoa (PB). Tese de Doutorado, Curso de Pós-Graduação em Sociologia, Universidade Federal de Pernambuco, Recife.

Alberto, M. de F. P. \& Mariano, M. S. S. (2003). Um estudo da representação social dos meninos em condição de rua sobre as drogas. In Coutinho, M. P. L., Lima, A. da S., Oliveira, F. B., \& Fortunato, M. L. (Orgs.). Representações sociais: abordagem interdisciplinar (pp. 312-329). João Pessoa: Editora Universitária/UFPB.

Bardin, L. (1979). Análise de Conteúdo. (L. A. Reto \& A. Pinheiro, Trads.). São Paulo: Edições 70/Martins Fontes. 
Lei 8.069, de 13 de julho de 1990. Estatuto da criança e do adolescente, Brasília, DF: Secretaria Especial dos Direitos Humanos. Ministério da Educação. Assessoria de Comunicação Social.

Campos, H. R., \& Alverga, A. R. de. (2001). Trabalho infantil e ideologia: contribuição ao estudo da crença indiscriminada na dignidade do trabalho. Estudos de Psicologia, 6 (2), 227-233.

Campos, T. N., Del Prette, Z. A. P. \& Del Prette, A. (2000). .Sobre(vivendo) nas ruas: habilidades sociais e valores de crianças e adolescentes. Psicologia: Reflexão e Crítica, 13 (3), 517-527.

Carlini, E. A., Carlini-Cotrim, B., \& Silva-Filho, A. R. (1990). Sugestões para programas de prevenção ao abuso de drogas no Brasil. São Paulo: Cebrid.

Cecconello, A. (2003). Resiliência e vulnerabilidade em famílias em situação de risco. Tese de Doutorado, Universidade Federal do Rio Grande do Sul, Porto Alegre.

Cruz, M. N. A. \& Assunção, A. A. (2008). Estrutura e organização do trabalho infantil em situação de rua em Belo Horizonte, MG, Brasil. Saúde e Sociedade, 17 (1), 131-142.

Dejours, C. (1986). Por um novo conceito de saúde. Revista Brasileira de Saúde Ocupacional, 14 (54), 7-11.

Dejours, C., Abdoucheli, E., \& Jayet, C. (1994). Psicodinâmica do trabalho: contribuições da Escola Dejouriana à análise da relação prazer, sofrimento e trabalho. São Paulo: Atlas.

Delegacia Regional do Trabalho (2007). DRT/PB faz balanço positivo das ações em 2006. Recuperado em 06 de outubro, 2008, de http://www.mte.gov.br/delegacias/pb/noticias/default4.asp>.

Fórum Nacional de Prevenção e Erradicação do Trabalho Infantil (2004). A evolução do trabalho infantil no Brasil de 1999 a 2001. Brasília: Unicef.

Grasciani, M. S. S. (1997). Pedagogia social de rua: análise e sistematização de uma experiência de vida. São Paulo: Cortez.

Kassouf, A. L. (2005). Trabalho infantil: causas e conseqüências. Estudo realizado para apresentação no concurso de Professor titular do Depto. de Economia. Recuperado em 06 de outubro, 2008, de http://www.cepea.esalq.usp.br/pdf/texto.pdf.

Koller, S. H. \& Hutz, C. S. (1996). Meninos e meninas em situação de rua: dinâmica, diversidade e definição. Coletâneas da ANPEPP: Aplicações da Psicologia na melhoria da qualidade de viva, 1 (12), 11-34.
Marques, W. E. U. (2001). Infâncias (pre) ocupadas: trabalho infantil, família e identidade. Brasília: Plano.

Minayo, M. C. de S. (1993). O limite da exclusão social: meninos e meninas de rua no Brasil. São Paulo: Hucitec/Abrasco.

Moreira, M. I. \& Stengel, M. (2003). Narrativas infanto-juvenis sobre o trabalho doméstico. Belo Horizonte: PUC Minas.

Moura, V. de C. (2004). Cartilha de prevenção ao uso de drogas. Fortaleza: Inesp.

Neiva-Silva, L. \& Koller, S. H. (2002). Adolescentes em situação de rua. In M. de L. J. Contini, S. H. Koller, \& M. N. dos Santos (Orgs). Adolescência e psicologia: concepções, práticas e reflexões críticas (pp. 112-121). Rio de Janeiro: Conselho Federal de Psicologia.

Oliveira, B. R. G. \& Robazzi, M. L. C. C. (2001). O trabalho na vida dos adolescentes: alguns fatores determinantes para o trabalho precoce. Revista Latino-Americana de Enfermagem, 9 (3), 83-89.

Organização Internacional do Trabalho - OIT (2001). Combatendo o trabalho infantil: guia para educadores. Brasília: IPEC.

Paludo, S. dos S. \& Koller, S. H. (2005). Resiliência na Rua: Um Estudo de Caso. Psicologia: Teoria e Pesquisa, 21 (2), 187-195.

Procuradoria Regional do Trabalho da $7^{\mathrm{a}}$ Região (2004). Malabarismo por alguns trocados. Recuperado em 06 de outubro, 2008, de http://www.prt7.mpt.gov.br/mpt_na_midia/2004/novembro/20_1 1_04_POVO_malabarismo_por_alguns_trocados.htm.

Sá, G. P. (1998). A construção do objeto de pesquisa em representações sociais. Rio de Janeiro: EDURJ.

Sidman, M. (1995). Coersão e suas implicações. São Paulo: Editorial Psy.

Yunes, M. A. M. (2001). A questão triplamente controvertida da resiliência em famílias de baixa renda. Tese de Doutorado, Pontifícia Universidade Católica de São Paulo, São Paulo.

Recebido em 02/04/07

Aceito em 26/11/2008

Endereço para correspondência : Daniele Cristine da Silva Cirino. Rua Benedito Henrique Silva, 77, Mangabeira, CEP 58056078, João Pessoa-PB, Brasil.E-mail: lunesdc@yahoo.es 